\title{
Outcome in hypertension complicating pregnancy in a tertiary care center
}

\author{
Chaitra S, Jayanthi, Akshita R Sheth, Renuka Ramaiah, Abhinaya Kannan, Mahantesh M
}

Correspondence: Dr. Chaitra S, Senior resident, Obstetrics and Gynaecology, ESIC PGIMSR and Model hospital, Bangalore, Karnataka, India; Email - chaittra.shiv@gmail.com

Distributed under Creative Commons Attribution-Share Alike 4.0 International.

\begin{abstract}
Objectives: The objective of this study was to identify the prevalence of the hypertensive disorder with some epidemiological factors. Methodology: This retrospective study was conducted at a tertiary care center, which included 286 hypertensive cases over a period of 1 year from January 2016 to December 2016. Data were gathered from medical record files. Results: Out of 3250 women delivered in the hospital 286 had hypertension, so the prevalence was $8.8 \%$. Out of 286 hypertensive pregnant women $80.06 \%$ were diagnosed as gestational hypertension, $14.68 \%$ as preeclampsia, $2.09 \%$ as eclampsia and $2.79 \%$ as chronic hypertension. Maximum number of women was nulliparous (46.85\%) and 21-25 years was the dominant age group $(46.15 \%)$. It is more prevalent at term (49.65\%). Eighty-two $(27.97 \%)$ mothers had a vaginal delivery, and $204(71.32 \%)$ had a cesarean delivery. Preterm delivery was the most prevalent morbid outcomes (28.67\%). Seventy-six (26.57\%) of the babies were categorized as low birth weight and $14.68 \%$ were diagnosed as intrauterine growth restriction. Conclusion: Hypertension in pregnancy is one of the common medical complications worsening the outcome of pregnancy.
\end{abstract}

Keywords: Hypertension, preeclampsia, eclampsia.

Hypertensive disorder in pregnancy is on the rise in today's world which is among one of the leading causes of both the maternal and perinatal morbidity and mortality ${ }^{1-3}$. In the developed countries, it ranked as the most common cause of maternal and perinatal morbidity and mortality, where as in developing countries anemia is still the most common. Systolic blood pressure reading of more than $140 \mathrm{mmHg}$ and a diastolic pressure of more than $90 \mathrm{mmHg}$ obtained at 6 hours interval after 20 weeks period of gestation is termed as hypertensive disorder in pregnancy. The acute elevation of blood pressure in pregnancy had several maternal complications like convulsions, abruptions, HELLP syndrome, hepatic and renal failure, retinal detachment and also rises the risk of heart attacks, cardiac failure, cerebrovascular accidents of the mother. Fetal complication is mainly due to the abnormal blood circulation from the mother to the fetus, which reduces the oxygen transfer to the fetus leading to condition like IUGR, premature delivery, foetal hypoxia to stillbirth, and higher rate of neonatal death ${ }^{2}$. Hypertension in pregnancy along with bleeding

Received: $16^{\text {th }}$ March 2017. Accepted: $4^{\text {th }}$ June 2017.

Chaitra S, Jayanthi, Sheth AR, Ramaiah R, Kannan A, Mahantesh M. Outcome in hypertension complicating pregnancy in a tertiary care center. The New Indian Journal of OBGYN. 2017; 4(1):42-6 
and infection are the most common causes of maternal mortality and morbidity ${ }^{4-7}$.

The American College of Obstetricians and Gynecologists (ACOG) and National High Blood Pressure Education Program Working Group on High Blood Pressure in Pregnancy has classified the hypertensive disorder in pregnancy into four major groups: 1) Gestational hypertension, where resting BP is $140 / 90 \mathrm{mmHg}$ or higher after the 20 week of gestation, 2) Chronic hypertension, that exists before pregnancy or begins in the first 20 weeks of gestation, 3) Preeclampsia (raised BP and edema or proteinuria)/eclampsia (preeclampsia and seizures), 4) Preeclampsia superimposed on chronic hypertension ${ }^{3,4}$, 8,9 . The pathology, clinical presentation and the outcome varies greatly with each category of cases ${ }^{10}$.

In spite of the very high incidence of the hypertensive disorder, even today the cause of the disease remains an unsolved one. After a very extensive clinical research, the cause is attributed to be immunological. This theory states that the abnormal trophoblastic invasion of the placenta, leads to the secretion of certain substances that activate vascular endothelial cells and damages them. These secretions have a vasoconstriction effect on all the systemic blood vessels leading to the rise of blood pressure.

Hypertensive disorder is more common among the nulligravidas and elderly women. Among the elderly women more so being the chronic hypertension superimposed by preeclampsia. It is a progressive disorder, which initiates at fertilization and courses until the total expulsion of the placenta. The changes occurring in the body will progress to a state of multi organ involvement increasing the mortality and morbidity in both the mother and the fetus ${ }^{4}$.

Medical management of the hypertensive disease does not prevent the fetal prognosis but studies have proven that early detection of the disease and treatment decreases both the hypertensive crises in the mother and reduces fetal complications. The use of antihypertensive is to prolong the pregnancy and slow down the progression of the disease until the period of viability reached in the fetus not compromising the mother. The choice of the antihypertensive is a challenge during pregnancy, and the dose calculation is difficult due to the physiological changes of pregnancy and the pathological changes of the disease. The commonly used drugs in pregnancy are methyldopa, beta-blockers, calcium channel blockers and vasodilators. Labetalol tops the chart, methyldopa is the oldest drug, which has been available for many years and is widely used. Studies support the use of betablockers and calcium channel blockers used in essential hypertension in pregnancy ${ }^{11}$.

Antihypertensive drug use during pregnancy is relatively common and increasing today, but the choice of which antihypertensive drug is less complex as only a small proportion of presently available drugs have been evaluated completely on pregnant women and many are contraindicated ${ }^{12}$. The objective of this study was to identify the prevalence of the hypertensive disorder, the contributor and associated factors, maternal and fetal outcome.

\section{Materials and Methods}

The study was performed at the ESIC PGIMSR and Model Hospital, a tertiary care center, Bangalore. This is a retrospective study, which included 286cases, studied over a period of 1 year from January 2016 to December 2016. Hypertension was identified based on the definition by the National Working Group Report on High Blood Pressure in Pregnancy, a recorded blood pressure of $>140 / 90 \mathrm{mmHg}$. Based on the signs and symptoms of the disease and a past history of hypertension before pregnancy, the patients were classified into the following groups of gestational hypertension, chronic Hypertension, preeclampsiaeclampsia and preeclampsia superimposed on chronic hypertension and eclampsia. The various data regarding demographic details, presenting complaints, gestational age, obstetrics history, diagnosis, blood pressure monitoring, current medications, antihypertensive drugs prescribed were gathered from medical record files. The collected data were tabulated and analyzed in SPSS software. 


\section{Results}

Of the total 3250 women delivered in the hospital 286 had hypertension (8.8\%). Two hundred thirty (80.4\%) women fell in the age group of $21-30$ years

Table 1: Demographic characteristics of the population $(\mathrm{N}=\mathbf{2 8 6})$

\begin{tabular}{lll}
\hline Variables & & Number (\%) \\
\hline Age in years & $<20$ & $24(8.39 \%)$ \\
& $21-25$ & $132(46.15 \%)$ \\
& $26-30$ & $98(34.26 \%)$ \\
& $31-35$ & $21(7.34 \%)$ \\
Parity & $>35$ & $11(3.84 \%)$ \\
& 0 & $134(46.85 \%)$ \\
& 1 & $76(26.5)$ \\
Period of gestation in & 2 & $42(14.68 \%)$ \\
weeks & 3 & $21(7.34 \%)$ \\
& $\geq 4$ & $13(4.54 \%)$ \\
& 30 & $32(11.18 \%)$ \\
& $>37$ & $112(39.16 \%)$ \\
& & $142(49.65 \%)$ \\
\hline
\end{tabular}

and $32(11.1 \%)$ were aged over 30 years. One hundred thirty four $(46.85 \%)$ were nulliparous (table 1$)$. The distribution of systolic and diastolic blood pressure in the mothers is illustrated in table 2. The maximum of the systolic blood pressure was $230 \mathrm{mmHg}$ and the maximum of the diastolic blood pressure was $140 \mathrm{~mm} \mathrm{Hg}$. Table 3 has the illustration of

\section{Table 2: Distribution of systolic and diastolic} blood pressure values $\quad(\mathrm{N}=286)$

\begin{tabular}{lll}
\hline Blood pressure (mm of Hg) & Number (\%) \\
\hline Systolic & $140-190$ & $252(88.1 \%)$ \\
& $>190$ & $34(11.8 \%)$ \\
Diastolic & $90-110$ & $190(66.4 \%)$ \\
& $>110$ & $96(33.5 \%)$ \\
\hline
\end{tabular}

the frequency distribution of different types of hypertension disorders in pregnancy. Out of 286 hypertensive pregnant women, $80.06 \%$ were diagnosed as gestational hypertension, $14.68 \%$ as preeclampsia, $2.09 \%$ as eclampsia and $2.79 \%$ as chronic hypertension.
Table 4 shows the maternal and fetal outcomes. Life threatening maternal complications like HELLP

\begin{tabular}{|c|c|}
\hline $\begin{array}{l}\text { Type of the hypertensive } \\
\text { disease }(\mathrm{N}=286)\end{array}$ & Number $(\%)$ \\
\hline Gestational hypertension & $229(80.06 \%)$ \\
\hline Preeclampsia-eclampsia & $42(14.68 \%)$ \\
\hline Chronic hypertension & $8(2.79 \%)$ \\
\hline $\begin{array}{l}\text { Preeclampsia superimposed } \\
\text { on Chronic hypertension }\end{array}$ & $1(0.34 \%)$ \\
\hline Eclampsia & $6(2.09 \%)$ \\
\hline
\end{tabular}

syndrome noted in $4.54 \%$ and abruption in $1.74 \%$. Intra operative couvelaire uterus was noted in two women with abruption and both of them had atonic post partum hemorrhage managed with blood and

\begin{tabular}{ll}
$\begin{array}{l}\text { Table 4. Prevalence of maternal } \\
\text { and fetal outcomes in the study } \\
\text { population (N=286) } \\
\text { Complications }\end{array}$ & Number (\%) \\
\hline HELLP syndrome & $13(4.54 \%)$ \\
Abruption & $5(1.74 \%)$ \\
Preterm & $82(28.67 \%)$ \\
Low birth weigh & $76(26.57 \%)$ \\
IUGR & $42(14.68 \%)$ \\
IUFD & $6(2.09 \%)$ \\
\hline
\end{tabular}

component transfusion. Preterm delivery was the most prevalent morbid outcomes (28.67\%). Seventy-six (26.57\%) of the babies were categorized under low birth weight and $14.68 \%$ were diagnosed as intrauterine growth restriction. Women with oligohydramnios and reduced weight for gestation were subjected to doppler to plan the further management. Eighty-two (27.97\%) mothers had a vaginal delivery, and 204 (71.32\%) had a cesarean delivery. Pregnancy was terminated by induction in $154(53.8 \%)$ cases, $47.05 \%$ of whom had a cesarean delivery. Elective cesarean delivery was performed in $18.53 \%$ (53) cases. The commonly used antihypertensive was beta-blockers followed by calcium channel blockers. 


\section{Discussion}

Hypertensive disorder in pregnancy even today continues to be a major problem in pregnant women even after extensive research. American Society of Nephrology reported an increased prevalence in preeclampsia in a rural area in developing countries ${ }^{13}$. Adverse maternal and fetal outcome associated with hypertension complicating pregnancy can be prevented by regular antenatal visits.

Roberts et al. studied 250 women with hypertensive disorder in pregnancy and they reported the prevalence to be $9.8 \%, 0.6 \%$ of which had chronic hypertension, $4.2 \%$ were diagnosed as preeclampsia, $0.3 \%$ women had preeclampsia superimposed on chronic hypertension, and $4.3 \%$ had gestation hypertension ${ }^{14}$. Whereas another study conducted in Nigeria, reported $5.3 \%$ of the population to be affected by hypertension complicating pregnancy, gestational hypertension, preeclampsia superimposed on chronic hypertension and preeclampsia-eclampsia were noted in $54.1 \%$, $26.2 \%$ and $19.7 \%$ respectively ${ }^{15}$. In this study we report the prevalence to be $8.8 \%, 80.06 \%$ had gestational hypertension, $14.68 \%$ had preeclampsiaeclampsia, $0.34 \%$ had preeclampsia superimposed on chronic hypertension, $2.79 \%$ had chronic hypertension and $2.09 \%$ had eclampsia.

The highest prevalence of the disorder was noted among the women $<20$ and $>32$ years and among the primigravidas which was similar to the results obtained by Shahla et al ${ }^{16}$. Yadav et al. ${ }^{17}$ concluded that the risk of PIH was higher when the age of pregnant women was less than 25 years, and this observation was in similarity with ours. A study by Mohanty et $\mathrm{al}^{18}$ reported that primiparous patients with PIH below 20 years of age was in $26 \%$ but only $15 \%$ of the controls were less than 20 years.

In this study, we observed the systolic blood pressure ranged between 140 to 230 and diastolic ranged from 90 to $140 \mathrm{mmHg}$, mean blood pressure being 185 and 115 for systolic and diastolic respectively. Similar results were noted in a study conducted by Buga et al in which included a total of 760 women, with an average blood pressure of
163.0/108.8 $\mathrm{mmHg}$, systolic pressure ranged from 140 to $270 \mathrm{mmHg}$, and diastolic from 90 to $190 \mathrm{mmHg}{ }^{19}$.

Placental abruption was noted in $1.74 \%$ of the women in this study which was relatively similar to $2 \%$ noted by Eshetu et $\mathrm{al}^{20}$, in contrast to a study by Hall et al conducted by which reported as high as $20 \%{ }^{21}$. HELLP syndrome was noted in $4.54 \%$ which was much lesser than $12.4 \%$ of the cases noted by Eshetuet al. ${ }^{20}$ and Prakash et al. reported HELLP syndrome in $7.5 \%$ of cases of preeclampsia ${ }^{22}$.

The fetal outcome was noted in the form of preterm deliveries, Apgar score, intrauterine growth restriction, low birth weight, the need for neonatal resuscitation, admission to neonatal intensive care unit and intrauterine fetal demise. Incidence of preterm delivery noted in $28.67 \%$, intrauterine growth restriction found in $14.68 \%$ of births, low birth weight in $26.57 \%$ and intrauterine fetal demise in 2.09. A study by Yadav et al. reported preterm deliveries in $28.8 \%$ which was similar to our result but a higher IUFD of $4.8 \%{ }^{17}$. In this study, we noted $27.97 \%$ mothers had vaginal delivery, and higher percentage $(71.32 \%)$ underwent cesarean section. Pregnancy was terminated by induction in $53.8 \%$ cases, $47.05 \%$ of whom had cesarean delivery. Elective cesarean delivery was performed in $18.53 \%$ cases.

\section{Conclusion}

Hypertension in pregnancy is associated with multiple and complicated complications in both the mother and baby. Presently screening modalities help early detection of the diseases and timely intervention of hypertensive disorders complicating pregnancy and provision of specialized systemic antenatal maternal care could reduce the impacts of such complications.

\section{Conflict of interest: None. Disclaimer: Nil.}

\section{References}

1)Henry CS, Biedermann SA, Campbell MF, Guntupalli JS. Spectrum of Hypertensive Emergencies in Pregnancy. Critical Care Clinics. 2004; 20: 607-712.

2)De Cherney AH, Nathan L, Laufer N, Roman AS. Current Diagnosis and Treatment - Obstetrics and 
Gynecology : Hypertension in Pregnancy . 11th Edition.

New York: McGraw Hill; 2012.

3)Report of the National High Blood Pressure Education Program Working Group on High Blood Pressure in Pregnancy. American Journal of Obstetrics and Gynecology. 2000; 183(1): S1-S22.

4)Cunningham FG, Leveno K, Bloom S, et al. Williams Obstetrics. 23rd Edition. New York: McGraw-HillMedical Publishing Division; 2010.

5)Vest AR, Cho LS. Hypertension in Pregnancy. Cardiology Clinics. 2012; 30: 407-23.

6)Wagner SJ, Barac S, Garovic VD. Hypertensive Pregnancy Disorders: Current Concepts. Journal of Clinical Hypertension. 2007; 9: 560-66.

7)Henry CS, Biedermann SA, Campbell MF, Guntupalli JS. Spectrum of Hypertensive Emergencies in Pregnancy. Critical Care Clinics. 2004; 20: 697-712.

8)Liu CM, Cheng PJ, Chang SD. Maternal Complications and Perinatal Outcomes associated with Gestational Hypertension and Severe Preeclampsia in Taiwanese Women. Journal Formes Medical Association. 2008; 107(2):129-38.

9)National High Blood Pressure Education Program Working Group Report on High Blood Pressure in Pregnancy. American Journal of Obstetrics and Gynecology. 1990; 163:1689-712.

10)Hnat MD, Sibai BM, Caritis S, Hauth J, Lindheimer MD, MacPherson C, et al. Perinatal Outcome in Women with Recurrent Preeclampsia Compared with Women Who Develop Preeclampsia as Nulliparas. American Journal of Obstetrics \& Gynecology. 2002; 20, 422-26.

11)Matthys LA, Coppage KH, Lambers DS, Barton JR, Sibai BM. Delayed postpartum preeclampsia: an experience of 151 cases. American Journal of Obstetrics and Gynecology. 2004; 190(5):1464-6.

12)Smith P, Anthony J, Johnson R. Review: Nifedipine in Pregnancy. British Journal of Obstetrics and Gynaecology. 2000; 107: 299-307.

13)American Society of Nephrology; News release, Nov. 8,2008 . Available from http://www.wrongdiagnosis.com/hd/news/62113 8.pregnant-rural-womenmore-at-risk.htm
14)Roberts CL, Albert CS, Morris JM, et al. Hypertensive Disorders in Pregnancy: A Population-Based Study. Medical Journal of Australia. 2005; 182: 332-35.

15)Vigil-De Garcia P, Montufar-Rueda C, Smith A. Pregnancy and Severe Chronic Hypertension: Maternal Outcome. Hypertension in Pregnancy. 2004; 23: 285-93.

16)Khosravi S, Dabiran S, Lotfi M, Asnavandy M. Study of the Prevalence of Hypertension and Complications of Hypertensive Disorders in Pregnancy. Open Journal of Preventive Medicine. 2014; 4: 860-67.

17)Yadav S, Yadav R, Saxena U. Hypertensive disorders of pregnancy and perinatal outcome. J Obset Gynecol India. 1997; 17: 322-30.

18)Mohanty S, Nayak N, Nanda NN, Rao P. Serum lipids and malondialdehyde levels in primiparous patients with pregnancy induced hypertension. Ind J of Clin Biochem. 2006; 21(1): 189-92.

19)Buga GA, Lumu SB. Hypertensive disorders of pregnancy at Umtata General Hospital: perinatal and maternal outcomes. East Afr Med J. 1999; 76(4): 217-22.

20)Seyom E, Abera M, Tesfaye M, Fentahun N. Maternal and fetal outcome of pregnancy related hypertension in Mettu Karl Referral Hospital, Ethiopia. J Ovarian Res. 2015; 8: 10.

21)Hall DR, Odendaal HJ, Steyn DW, Grové D. Expectant management of early onset, severe preeclampsia: maternal outcome. BJOG. 2000; 107(10): 1252-7.

22)Prakash J, Pandey LK, Singh AK, Kar B.

Hypertension in pregnancy: hospital based study. J Assoc Physicians India. 2006; 54: 273-78.

\section{Chaitra S1, Jayanthi' ${ }^{2}$, Akshita R Sheth ${ }^{3}$, Renuka Ramaiah", Abhinaya Kannan', Mahantesh M6}

${ }^{1}$ Senior resident; ${ }^{2}$ Junior resident; ${ }^{3}$ Senior resident; ${ }^{4} \mathrm{Head}$ of the department of Obstetrics and Gynaecology; ${ }^{5}$ Junior resident; ${ }^{6}$ Junior resident, Department of Obstetrics and Gynaecology, ESIC PGIMSR and Model hospital, Bangalore, Karnataka, India. 